\title{
Pseudocyst of the Pancreas in Childhood
}

\author{
Major C L Griffiths, \\ MB, FRCS, RAMC \\ British Military Hospital, Rinteln, BFPO 29
}

\begin{abstract}
SUMMARY: Pancreatic cysts are uncommon in childhood. Over half of those reported are caused by trauma. A case re is presented and the management of this patient discussed with reference to information from previous reports.
\end{abstract}

\section{Case Report}

An 8-year-old boy was admitted to BMH Rinteln with severe left upper quadrant pain. He gave a history of having been kicked in the abdomen by his brother during play 3 weeks previously. The pain had become worse and he then developed anorexia, listlessness and had lost 3 $\mathrm{kg}$ in weight. On examination he was pale and had an obvious tender diffuse mass involving the epigastrium and left upper quandrant. Investigations: $E S R=48$ in first hour, $\mathrm{Hb}=13.2$ gram per cent, $\mathrm{WBC}=6.0 \times 10^{9} / 1$. An IVU was normal but ultrasound scan showed a transonic collection anterior to the superior pole of the left kidney consistent with the clinical diagnosis of a subcapsular splenic haematoma.

For 5 days his symptoms improved only to deteriorate over the subsequent 2 weeks with anorexia and vomiting. The blood profile was normal except an ESR $=32$ and a polymorph leucocytosis of $83 \%$. Repeat ultrasound scan showed one large cyst and several smaller cysts in the splenic region. Barium meal suggested there was a mass behind the stomach displacing it forward. At this stage the plasma amylase $=3089$ International units.

Laparotomy confirmed the presence of a large lesser sac cyst (pseudocyst) with multiple smaller cysts of the pancreas each $2-3 \mathrm{cms}$ in diameter. The smaller cysts of the pancreas were marsupialised and the lesser sac was drained through a wide bore tube drain to the exterior through a separate stab incision.

Postoperatively he made slow but steady progress. An external fistula formed in the laparotomy wound 2 weeks following operation but resolved over 3 weeks. Ultrasound scan at this stage showed resolution of the cysts, $\mathrm{Hb}=12.2 \mathrm{gm} \%, \mathrm{WBC}=5.0 \times 10^{\circ} / \mathrm{L}$ and amylase $=$ 257 Somogyi units. The patient has made a complete recovery.

\section{Discussion}

Pseudocyst of the pancreas is uncommon in childhood; only 113 cases are reported in persons under 18 years of age up to 1981 . The mean age of the reported cases is 7.5 years with an age range of 2 months to 17 years. $^{2}$ Boys appear to be affected twice as often as girls and trauma is the initiating cause in well over $50 \%$ of cases. ${ }^{3}$
Kicks, bicycle handlebars and child abuse are the m\$s common forms of trauma implicated. In the remaind啇, $4 \%$ of cases follow mumps and acute pancreatitis, a small percentage are due to gastric duplication, hereditary pancreatitis and malnutrition, but $30 \%$ of all cases are $\omega_{f}$ unknown aetiology. ${ }^{3}$

Symptoms most frequently complained of are dominal pain or a feeling of fullness, nauseaçaţd vomiting, anorexia and weight loss. On examinatiog tan abdominal mass is present in $64 \%$ of cases and $80 \% 0 \Rightarrow$ patients have an elevated serum amylase. ${ }^{2}$ Ultras scanning is now recognised as the most effective mesth for diagnosis; cysts as small as $3 \mathrm{cms}$ may be identffied. Barium meal may identify a large lesser sac colleetiog.

Management of this rare condition in children has, ân recently, been conducted on adult pseudocyst maxagement policies. In adults $50 \%$ of pseudocysts may regiress spontaneously; ${ }^{4}$ however in children the pancreatitis cyst formation causes such systemic upset that eas ly surgical intervention is the best method of treatment. The surgical procedure most commonly used is that of inter. nal drainage by cystogastrostomy or less usually by Ro $\overrightarrow{\vec{x}}$ en $Y$ cystojejunostomy. Cystogastrostomy is technicafly easy and has the lowest rate of recurrence and operat mortality. External drainage or marsupialisation us firm rubber or silicone drains has been advocated ${ }^{5}$ a $\mathrm{Pd}$ was the method used in this case. The argument agai this therapy is its high recurrence rate $(25 \%)$ and cutaneous fistula formation with the associated electrolotte loss, skin excoriation and enzyme loss. However, in series reported by Pokorny et al, the fistula resolved sportaneously as occurred in this case.

Recently external drainage in the form of percutanedis fine needle aspiration using ultrasound as a guide inas achieved excellent results. ${ }^{6}$ Recurrence of the cyst formation has been lessened by a recent modification whereby the 16 gauge Teflon intravenous catheter used for percutaneous aspiration is left in place to allow complete drainage. There have been no complications and the technique is well tolerated. Complete excision of the cidot carried a high mortality $(10 \%)^{1}$ because of sevfe haemorrhage and damage to adjacent organs as the cyst wall is not well formed in this age group and dissection is difficult. Non-operative treatment of a pseudocyst is 
reserved for those children whose symptoms are improving in association with resolution of the cyst on utrasound scan.

\section{Conclusion}

Pancreatic pseudocyst in children is uncommon. The case reported highlights the presentation and management with the excellent outlook for cure. The recurrence rate is low after internal drainage, but recently percutaneous fine needle aspiration has revealed equally good results. The disease pathogenesis seems to be non-progressive in children when compared with the adult form due to lack of pancreatic insult from alcohol ingestion or secondary to biliary tract pathology.

\section{Acknowledgement}

I wish to thank Colonel W G Johnston for his help and encouragement in writing this article about his patient.

\section{REFERENCES}

1. Kagan, R J, et al. Pseudocyst of the pancreas in childhood. Arch Surg 1981; 116: 1200-03.

2. CoOney, D R, Grosfield, J. L. Operative management of pancreatic pseudocysts in infants. Ann Surg 1975; 182: 590-596.

3. Grosfield, J L, CoOney D R. Pancreatic and gastrointestinal trauma in children. Paediatr Clin North Am 1975; 22: 365-377.

4. BRADIFY, E L, CLEMENTS L J. Spontaneous resolution of pancreatic pseudocysts. Am J Surg 1975; 219: 23-28.

5. POKOR\Y, W J, Raftensperger J G, Harberg F J. Pancreatic pseudocysts in children. Surg Gynaecol Obstet 1980; 151: $182-4$

6. Windle, R, Finlay D, NeOptolemos J P. Needle aspiration in the treatment of pancreatic pseudocyst in childhood. Ann R Coll Surg 1983; 65. 